\title{
Oleate-mediated activation of phospholipase D and mammalian target of rapamycin (mTOR) regulates proliferation and rapamycin sensitivity of hepatocarcinoma cells
}

\author{
C. Arous • M. Naïmi • E. Van Obberghen
}

Received: 27 September 2010 / Accepted: 3 December 2010 / Published online: 15 January 2011

(C) Springer-Verlag 2011

\begin{abstract}
Aims/hypothesis A high-fat diet and obesity are associated with increased risk of liver cancer. Because increased delivery of NEFA to the liver occurs in these conditions, we investigated the involvement of the unsaturated fatty acid oleate in hepatocarcinoma cell proliferation using humanderived hepatocarcinoma cell lines as model systems.

Methods Western blotting, FACS analysis and $\left[{ }^{3} \mathrm{H}\right]$ thymidine incorporation were used to study the signalling pathways and the proliferation of cells cultured for up to $72 \mathrm{~h}$ with or without a concentration of oleate considered to be relevant to human pathophysiology $(50 \mu \mathrm{mol} / \mathrm{l})$ or a concentration considered elevated $(1 \mathrm{mmol} / \mathrm{l})$.

Results In HepG2 cells, proliferation was increased in the presence of $50 \mu \mathrm{mol} / \mathrm{l}$ oleate, but was decreased at $1 \mathrm{mmol} /$ 1. This differential effect was correlated with the activation of the mammalian target of rapamycin complex 1 (mTORC1) and with increased translation of cell cycle regulators. Oleate-mediated $\mathrm{mTORC} 1$ activation required phospholipase D activation, which produces phosphatidic acid and is known to render mTORC1 rapamycin resistant.
\end{abstract}

C Arous and M Naïmi contributed equally to this study.

C. Arous $\cdot$ M. Naïmi $\cdot$ E. Van Obberghen

Faculté de Médecine,

Institut de Génétique et Signalisation Moléculaire (IFR50),

Université de Nice-Sophia Antipolis,

Nice, France

C. Arous $(\bowtie) \cdot$ M. Naïmi $\cdot$ E. Van Obberghen

INSERM U907,

06107 Nice, France

e-mail: arous@unice.fr

M. Naïmi • E. Van Obberghen

Laboratoire de Biochimie, Hôpital Pasteur, CHU de Nice,

Avenue de Valombrose,

Nice 06200, France
Remarkably, rapamycin resistance was found to affect specifically the mTORC1/eukaryotic initiation factor 4Ebinding protein 1 (4E-BP1) branch of the mTORC1 pathway in the presence of $50 \mu \mathrm{mol} / \mathrm{l}$ oleate. Furthermore, inhibition of phosphatidic acid production abolished oleateinduced increases in mTORC1 activity and cyclin A production. Importantly, the same differential effects of oleate on mTORC1 activation, cell cycle regulators and rapamycin resistance were found in SK-Hep1 cells.

Conclusions/interpretation Oleate stimulates mTORC1 activation and rapamycin resistance. We propose that rapamycin-derived mTOR inhibitors are likely to be of limited therapeutic use to restrain hepatic tumour growth, particularly in the context of associated obesity.

Keywords Liver cancer-mTORC1 - Oleate

Phospholipase D · Proliferation · Rapamycin resistance

$\begin{array}{ll}\text { Abbreviations } \\ \text { 4E-BP1 } & \text { Eukaryotic initiation factor 4E-binding protein 1 } \\ \text { HCC } & \text { Hepatocellular carcinoma } \\ \text { mTORC1 } & \text { Mammalian target of rapamycin complex 1 } \\ \text { PA } & \text { Phosphatidic acid } \\ \text { PKB } & \text { Protein kinase B } \\ \text { PLD } & \text { Phospholipase D } \\ \text { PTEN } & \text { Phosphatase and tensin homologue } \\ \text { S6 } & \text { Ribosomal protein S6 } \\ \text { S6K } & \text { p70 S6 kinase }\end{array}$

\section{Introduction}

Hepatocellular carcinoma (HCC) is the third leading cause of cancer-related death worldwide [1] and the most frequent 
form of liver cancer. HCC is thought to occur in response to chronic liver injury, which may drive compensatory hyperproliferation of transformed hepatocytes [2]. Chronic liver injury can result from alcohol consumption, viral infection or the progression of non-alcoholic fatty liver disease (NAFLD) to non-alcoholic hepatosteatitis (NASH) [3]. In agreement with this, epidemiological observations have revealed a link between high-fat diet feeding/obesity and the risk of HCC. Indeed, high-fat feeding and obesityassociated insulin resistance increase the delivery of NEFA to the liver, which, together with increased liver lipogenesis, contributes to NAFLD development and liver regeneration [4]. Furthermore, obesity-associated low-grade chronic inflammation favours NAFLD progression to NASH [5].

NEFA have the intrinsic potential of inducing both liver damage and compensatory hyperproliferation. The saturated NEFA palmitate is known to promote liver damage and to exert lipotoxic effects on hepatocytes [6]. Conversely, the unsaturated NEFA oleate has recently been shown to increase HepG2 hepatoma proliferation through an mTOR-dependent mechanism [7]. According to the authors, the subsequent increase in cell proliferation could involve protein kinase $\mathrm{B}$ (PKB) activation. However, another study does not support PKB activation as the mechanism promoting hepatoma proliferation in obese mice [8]. Indeed, PKB activation in the liver is blunted in the context of obesity and insulin resistance.

Alternative means used by oleate to stimulate hepatoma proliferation could be directly related to the activation of the mammalian target of rapamycin complex 1 (mTORC1). First, this pathway is known to be crucial for cell growth and proliferation [9]. Furthermore, its activation was shown to be increased in the liver of HCC-bearing obese mice, whereas PKB activation was shown to be decreased [8]. While the ability of NEFA to activate the mTOR pathway was described several years ago, the underlying mechanism remains poorly defined [10]. The mTOR kinase responds to growth factors, amino acids, energy or stress signals to control cell growth, proliferation, survival and metabolism [11]. Depending on its partners, mTOR forms two distinct multiprotein complexes, mTORC1 and mTORC2, which exhibit different sensitivities to the immunosuppressant drug rapamycin and display different substrate specificities. The two main substrates of mTORC1 are the translational regulators p70 S6 kinase (S6K) and eukaryotic initiation factor 4E-binding protein 1 (4E-BP1), whereas mTORC2 phosphorylates $\mathrm{PKB}$ on serine 473 . In addition, regulation of the mTORC1 pathway through the binding of the lipid messenger phosphatidic acid (PA) to mTOR [12, 13] and S6K [14] has been described. PA is produced through the activity of phospholipase D (PLD) isozymes, among which PLD2 has been shown to be concentration-dependently regulated by oleate [15]. Thus, one would expect that oleate-mediated activation of $\mathrm{mTORC} 1$ may, at least in part, rely on PLD activity. Interestingly, the activity of PLDs is increased in numerous cancers, and has been suggested to favour the survival/metastatic potential of cancer cells and to render them rapamycin resistant [16]. Moreover, elevated PLD-mTOR signalling has been suggested to mediate the Warburg effect [17], a metabolic shift characteristic of cancer cells that provides them with the energetic fuels needed for cell growth [18].

To sum up, a large amount of information on the implication of NEFA in cancer biology prompted us to revisit the mechanisms by which oleate may influence the proliferation and related growth signalling pathways in two human hepatocarcinoma cell lines, HepG2 and Sk-Hep1, which we used as model systems.

\section{Methods}

Antibodies and other reagents DMEM and Eagle's minimum essential medium (EMEM) were purchased from Gibco Laboratories (Invitrogen, Cergy Pontoise, France) and ATCC (Manassas, VA, USA), respectively. Bovine Serum Albumin fraction $\mathrm{V}$, fatty acid free (catalogue no. 04-100-814) was from Euromedex (Souffelweyersheim, France). Oleic acid conjugated to fatty acid-free BSA (O3008), rapamycin and hepatocyte growth factor were purchased from Sigma-Aldrich (St Quentin-Fallavier, France). [Methyl- $\left.{ }^{3} \mathrm{H}\right]$ thymidine was purchased from Perkin-Elmer (Courtaboeuf, France). Antibodies directed to cyclin A and E were from Santa Cruz Biotechnology (Heidelberg, Germany). Antibody to $\alpha$-tubulin was from Sigma-Aldrich (Lyon, France). All other antibodies were purchased from Cell Signaling Technology (Ozyme, Montigny le Bretonneux, France).

Cell culture conditions and treatments HepG2 and SKHep1 cells (HB-8065 and HTB-52; ATCC) were, respectively, cultured in DMEM or EMEM supplemented with 10\% (vol./vol.) FCS, $40 \mathrm{U} / \mathrm{ml}$ penicillin and $40 \mu \mathrm{g} / \mathrm{ml}$ streptomycin in a $5 \% \mathrm{CO}_{2}$ atmosphere at $37^{\circ} \mathrm{C}$. For most experiments, $4 \times 10^{5}$ cells were grown in six-well plates in medium containing 10\% (vol./vol.) FCS for $16 \mathrm{~h}$. Thereafter, the medium was replaced with DMEM or EMEM containing fatty acid-free BSA (control condition), or conjugated to $50 \mu \mathrm{mol} / 1$ or $1 \mathrm{mmol} / 1$ oleic acid for the indicated times (medium was replaced every $24 \mathrm{~h}$ ). The effects of $50 \mu \mathrm{mol} / 1$ or $1 \mathrm{mmol} / 1$ oleate were compared with the corresponding $\mathrm{BSA}$ conditions, $\mathrm{BSA}_{50 \mu \mathrm{mol} / 1}$ $(0.025 \mathrm{mmol} / \mathrm{l} \mathrm{BSA})$ or $\mathrm{BSA}_{1 \mathrm{mmol} / 1}(0.5 \mathrm{mmol} / \mathrm{l} \mathrm{BSA})$, respectively, as different amounts of $\mathrm{BSA}$ were required to conjugate $50 \mu \mathrm{mol} / \mathrm{l}$ vs $1 \mathrm{mmol} / \mathrm{l}$ oleate. However, only the 
$\mathrm{BSA}_{1 \mathrm{mmol} / 1}$ control condition is presented, as no differences were found between $\mathrm{BSA}_{50 \mu \mathrm{mol} / 1}$ and $\mathrm{BSA}_{1 \mathrm{mmol} / 1}$. When indicated, rapamycin or hepatocyte growth factor (HGF) was used at $50 \mathrm{nmol} / \mathrm{l}$ or $50 \mu \mathrm{g} / \mathrm{ml}$, respectively. 1-Butanol and tert-butanol were used at $0.6 \%$ (vol./vol.). When indicated, cells cultured in medium containing $10 \%$ (vol./vol.) FCS were used as a positive control.

Oil Red O staining and triacylglycerol content determination Cells cultured for $24 \mathrm{~h}$ were washed twice with PBS and fixed in 4\% (vol./vol.) paraformaldehyde in PBS for 20 min. After washing, cells were stained with Oil Red O for $20 \mathrm{~min}$ at room temperature and images were captured under a microscope. For quantitative analysis of cellular triacylglycerol, Oil Red O-stained cells were rinsed exhaustively with PBS before addition of $200 \mu$ lisopropyl alcohol. The extracted dye was removed and its absorbance was monitored at $510 \mathrm{~nm}$ as described [19].

Cell counting and FACS analysis of cell viability Cells cultured for 24, 48 and $72 \mathrm{~h}$ were trypsinised and counted with a haemocytometer. For FACS analysis, both floating and adherent cells were washed and stained with $25 \mu \mathrm{g} / \mathrm{ml}$ propidium iodide in PBS, $2 \mathrm{mmol} / \mathrm{l}$ EDTA, 1\% (wt/vol.) BSA. Propidium iodide-positive cells were counted by analysis of $1 \times 10^{4}$ cells with a FACScan flow cytometer using Cell Quest Pro software (Becton Dickinson, Mountain View, CA, USA). Results were normalised with respect to the control condition.

$\left[{ }^{3} H\right]$ thymidine incorporation Cells were cultured for $72 \mathrm{~h}$ as described except that $37 \mathrm{kBq}(1 \mu \mathrm{Ci})\left[{ }^{3} \mathrm{H}\right]$ thymidine was added $4 \mathrm{~h}$ before the medium was removed. Incorporated $\left[{ }^{3} \mathrm{H}\right]$ thymidine was precipitated by the addition of $10 \%$ (vol./vol.) trichloroacetic acid (TCA) for $30 \mathrm{~min}$ on ice. Cells rinsed with 5\% (vol./vol.) TCA were lysed with $400 \mu \mathrm{l}$ of $0.2 \mathrm{~mol} / \mathrm{l} \mathrm{NaOH}$ and neutralised with an equal volume of $\mathrm{HCl}$. Lysates were transferred in scintillation buffer and assayed for radioactivity in a scintillation counter.

PLD activity measurement and suppression of PA production by alcohol trap assay Cells cultured for $72 \mathrm{~h}$ were washed in PBS and lysed by three freeze-thaw cycles in a solution of $150 \mu \mathrm{l}$ ice-cold $250 \mathrm{mmol} / \mathrm{l}$ Tris, $25 \mathrm{mmol} / \mathrm{l}$ $\mathrm{CaCl}_{2}, \mathrm{pH}$ 8. Then, $50 \mu \mathrm{l}$ of lysate was incubated for $1 \mathrm{~h}$ at $37^{\circ} \mathrm{C}$ with Amplex Red reaction buffer (Amplex Red Phospholipase D Assay Kit; Molecular Probes, Invitrogen) and PLD activity was estimated with a Synergy 4 fluorometer (Biotek, Colmar, France). A standard curve was generated with purified PLD from Streptomyces chromofuscus (Sigma-Aldrich). All results were normalised with respect to the protein concentration of the lysate (BCA
Assay; Interchim, Montluçon, France). For PLD inhibition experiments, cells were cultured for $72 \mathrm{~h}$ with DMEM supplemented with $0.6 \%$ (vol./vol.) of 1-butanol or tertbutanol; cell extracts were analysed by western blotting.

Western blot analysis Cells were scraped and incubated for $20 \mathrm{~min}$ in ice-cold lysis buffer [20]. The lysates were centrifuged at $13,000 \times \mathrm{g}$ for $20 \mathrm{~min}$ at $4^{\circ} \mathrm{C}$, and protein concentrations were determined by the $\mathrm{BCA}$ colorimetric assay. Lysates were subjected to SDS-PAGE gel electrophoresis and transferred to polyvinylidene fluoride membranes (Bedford, MA, USA). Membranes were presoaked in blocking buffer and incubated with antibodies, according to the manufacturer's instructions. Results were normalised with respect to $\alpha$-tubulin levels and the BSA condition used as control was arbitrarily assigned a value of 1 .

Statistical analysis Experiments were performed at least three times and results are presented as mean \pm SEM, and $p$ values were determined by the unpaired Student's $t$ test. Results were considered significant when $p<0.05$.

\section{Results}

Concentration-dependent effect of oleate on HepG2 steatosis and proliferation We first compared the effect of BSA vs BSA-conjugated oleic acid on triacylglycerol accumulation in HepG2 cells (Fig. 1a, b). Treatment of HepG2 cells with oleate for $24 \mathrm{~h}$ induced concentration-dependent triacylglycerol accumulation compared with the control condition, with up to a 2.7 -fold increase observed at $1 \mathrm{mmol} / \mathrm{l}$ oleate. To evaluate the effect of oleate on cell proliferation (Fig. 2a), fetal FCS and HGF were used as controls to increase and decrease HepG2 proliferation, respectively [21]. Compared with the number of cells initially plated, all treatments except $1 \mathrm{mmol} / \mathrm{l}$ oleate and HGF led to a significantly increased cell number at the $72 \mathrm{~h}$ time point. When comparing the effect of BSA with that of BSA-conjugated oleate, divergent results were observed between $50 \mu \mathrm{mol} / \mathrm{l}$ and $1 \mathrm{mmol} / \mathrm{l}$ oleate. Indeed, exposure to $50 \mu \mathrm{mol} / \mathrm{l}$ oleate significantly increased the cell number after $72 \mathrm{~h}$ treatment, whereas $1 \mathrm{mmol} / \mathrm{l}$ oleate had no significant effect. We next analysed $\left[{ }^{3} \mathrm{H}\right]$ thymidine incorporation and the number of propidium iodine-positive cells after $72 \mathrm{~h}$ of treatment with BSA, $50 \mu \mathrm{mol} / 1$ or $1 \mathrm{mmol} / \mathrm{l}$ oleate, FCS or HGF. As seen in Fig. 2b, $\left[{ }^{3} \mathrm{H}\right]$ thymidine incorporation was increased by $50 \mu \mathrm{mol} /$ 1 oleate and FCS but decreased by $1 \mathrm{mmol} / \mathrm{l}$ oleate and by HGF, albeit not significantly for the latter. Conversely, the number of propidium iodine-positive cells was unchanged by FCS or HGF but significantly decreased by $50 \mu \mathrm{mol} / \mathrm{l}$ and further decreased by $1 \mathrm{mmol} / \mathrm{l}$ oleate (Fig. 2c), indicating that 
a

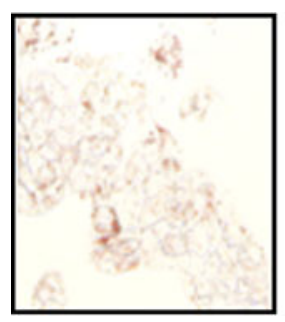

BSA

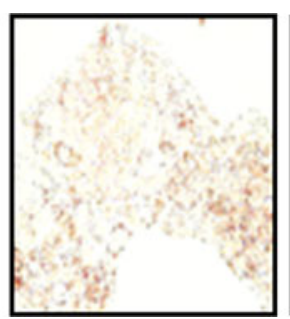

$50 \mu \mathrm{mol} / 1$

$\mathrm{OA}$

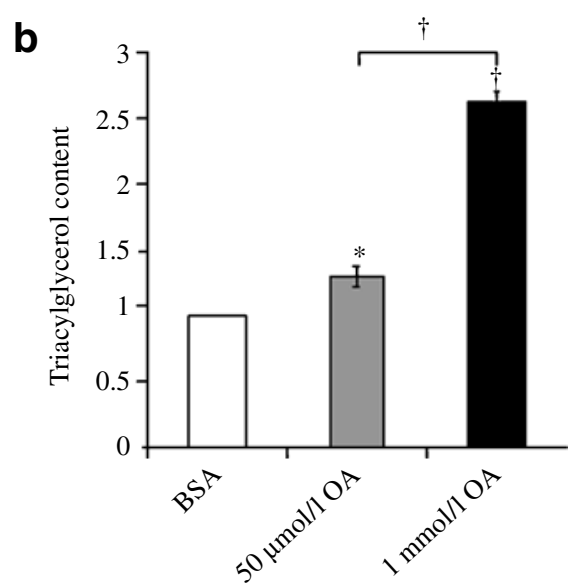

Fig. 1 Concentration-dependent effect of oleic acid (OA) on HepG2 steatosis. a Oil Red O staining of HepG2 cells treated with BSA or $50 \mu \mathrm{mol} / \mathrm{l}$ or $1 \mathrm{mmol} / \mathrm{l}$ oleate for $24 \mathrm{~h}$. b Triacylglycerol content of HepG2 cells treated with BSA or $50 \mu \mathrm{mol} / 1$ or $1 \mathrm{mmol} / 1 \mathrm{OA}$ for $24 \mathrm{~h}$ determined by an Oil Red O-based colorimetric assay at $510 \mathrm{~nm}$ $(n=3)$. Results were normalised with respect to the BSA condition. ${ }^{*} p<0.05,{ }^{\dagger} p<0.001$

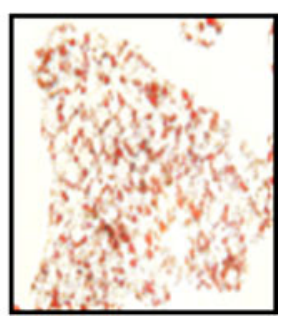

$1 \mathrm{mmol} / \mathrm{l}$

$\mathrm{OA}$ increasing the oleate concentration indeed protects against cell death.

In summary, our results show that $50 \mu \mathrm{mol} / 1$ oleate increases HepG2 cell number by concomitantly increasing cell proliferation and decreasing cell death.

Oleate-mediated proliferation of HepG2 cells involves the regulation of cell cycle components The differential effects on cell proliferation induced by the low vs high concentration of oleate prompted us to search for a differential modulation of known cell cycle regulators produced by these treatments. Notably, hyperphosphorylation of the cellcycle regulator retinoblastoma protein $(\mathrm{RB})$ and increased production of cyclin $\mathrm{A}$ and $\mathrm{E}$ have been implicated in $\mathrm{HCC}$ initiation and progression [22, 23]. As seen in Fig. 3a-d, a $24 \mathrm{~h}$ treatment with the low concentration of oleate increased the level of phosphorylated RB and the protein levels of cyclin A and E. In contrast, the high concentration of oleate decreased phosphorylated RB and had no significant effect on cyclin A and E protein levels. Similar results were observed with a $72 \mathrm{~h}$ treatment (data not shown). Furthermore, exposure to oleate had no effect on cyclin A and E transcript levels, which suggests a translational effect of oleate on their respective mRNAs (data not shown).

Thus, these early effects of oleate on cell-cycle components are likely to explain its proliferative action.

Oleate drives mTORC1-dependent HepG2 proliferation and induces resistance to rapamycin We took advantage of the concentration-dependent effects of oleate treatment to search for the signalling pathways potentially involved in oleate-induced proliferation. We reasoned that the relevant pathway would be differentially regulated by the low vs

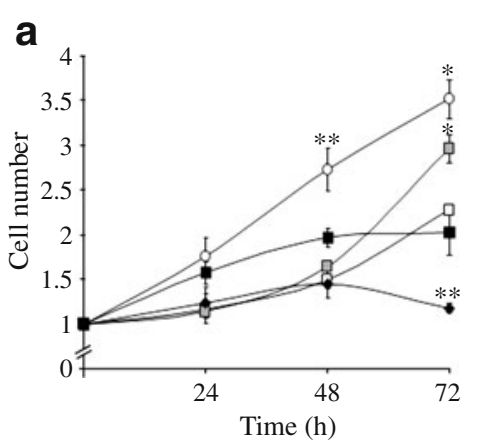

b

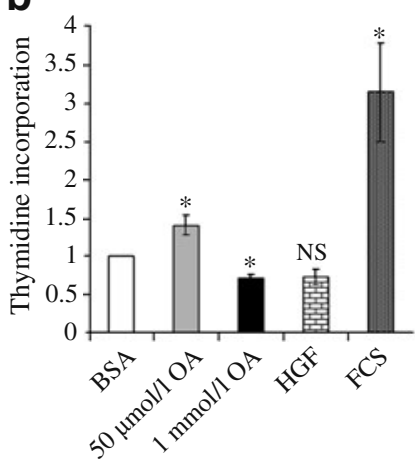

C

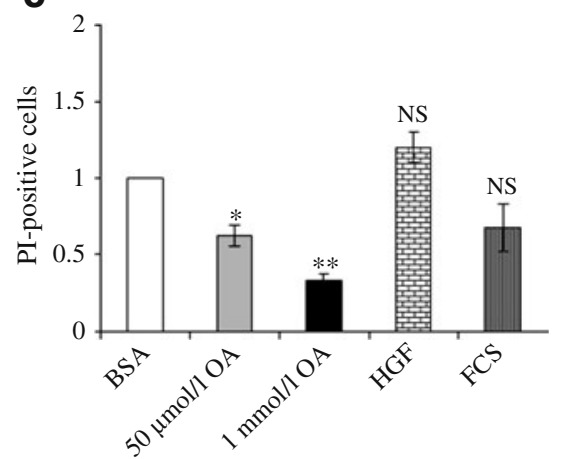

Fig. 2 Concentration-dependent effect of oleic acid (OA) on HepG2 proliferation. a Proliferation of HepG2 cells exposed to BSA, $50 \mu \mathrm{mol} / 1$ or $1 \mathrm{mmol} / 1 \mathrm{OA}, 50 \mathrm{ng} / \mu \mathrm{l} \mathrm{HGF}$ or $10 \%$ (vol./vol.) FCS for 24,48 or $72 \mathrm{~h}$ assessed by counting viable cells with a haemocytometer at the corresponding time points (white squares, BSA; grey squares, $50 \mu \mathrm{mol} / 1 \mathrm{OA}$; black squares, $1 \mathrm{mmol} / 1 \mathrm{OA}$; white circles, FCS; black diamonds, HGF $50 \mathrm{nmol} / \mathrm{l}, n=3$ ). b Proliferation of
HepG2 cells exposed to BSA, $50 \mu \mathrm{mol} / 1$ or $1 \mathrm{mmol} / 1 \mathrm{OA}, 50 \mathrm{ng} / \mu \mathrm{l}$ HGF or $10 \%$ (vol./vol.) FCS for $72 \mathrm{~h}$ assessed by $\left[{ }^{3} \mathrm{H}\right]$ thymidine incorporation $(n=4)$. c Viability of HepG2 cells exposed to BSA, $50 \mu \mathrm{mol} / 1$ or $1 \mathrm{mmol} / \mathrm{l} \mathrm{OA}, 50 \mathrm{ng} / \mu \mathrm{HGF}$ or $10 \%$ (vol./vol.) FCS for $72 \mathrm{~h}$ assessed by FACS analysis of propidium iodine (PI)-positive cells $(n=3)$. Results were normalised with respect to the BSA condition. $* p<0.05, * * p<0.01$ 
a

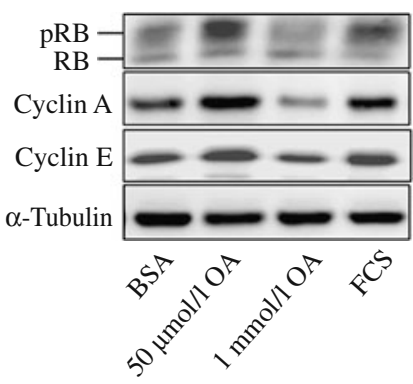

C

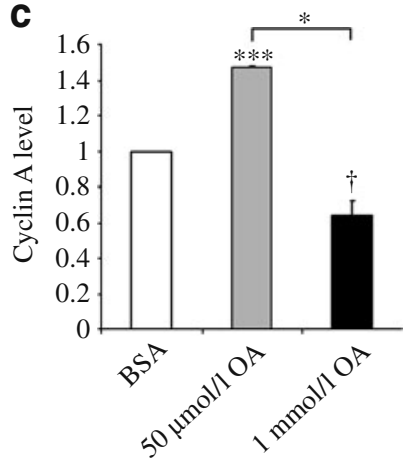

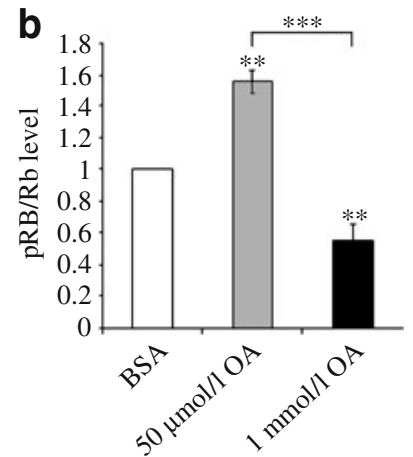

d

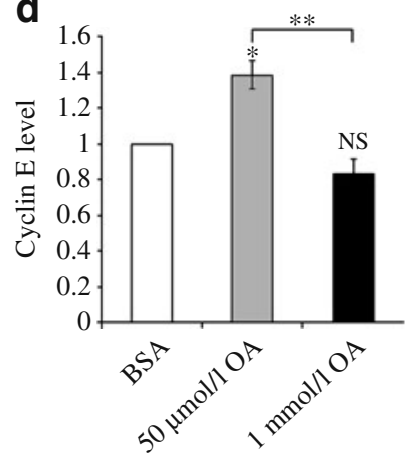

Fig. 3 Oleic acid (OA) regulates the level and activation of cell cycle components. a Representative blots showing the level of RB phosphorylation (pRB) and levels of cyclin A and E in HepG2 cells exposed to BSA, $50 \mu \mathrm{mol} / 1$ or $1 \mathrm{mmol} / \mathrm{l} \mathrm{OA}$ or $10 \%$ (vol./vol.) FCS for $24 \mathrm{~h}$. b-d Quantification of RB phosphorylation (b), cyclin A level (c) and cyclin E (d) level in HepG2 cells exposed to BSA, $50 \mu \mathrm{mol} / 1$ or $1 \mathrm{mmol} / 1 \mathrm{OA}$ for $24 \mathrm{~h}(n=3)$. Results in b-d were normalised with respect to the BSA condition. ${ }^{*} p<0.05,{ }^{*} p<0.01$, $* * * p<0.001,{ }^{\dagger} p=0.052$

high concentration of oleate. Among the potentially relevant candidate cascades, we examined the extracellular signal-regulated kinase (ERK)1/2, PKB and mTORC1 phosphorylation levels, and phosphatase and tensin homologue (PTEN) level by western blot analysis of HepG2 cells treated with $50 \mu \mathrm{mol} / \mathrm{l}$ or $1 \mathrm{mmol} / \mathrm{l}$ oleate (Fig. $4 \mathrm{a}-\mathrm{e}$ ). A $24 \mathrm{~h}$ treatment with the low and high oleate concentrations had a similar effect on ERK and PKB activation, i.e. it reduced ERK and increased PKB. Both concentrations were without effect on PTEN level. Interestingly, we observed a differential effect of oleate on markers of the activity of the mTORC1 pathway (Fig. 5a-d). Indeed, at a low concentration, oleate increased the phosphorylation of mTOR, that of its target 4E-BP1 and that of the ribosomal S6 protein, the downstream target of S6K. Importantly, the high concentration of oleate had the opposite effect on the phosphorylation state of these molecules. Similar results were observed with a $72 \mathrm{~h}$ treatment (data not shown).

To further illustrate the concentration-dependent effects of oleate on mTORC1 activation and cyclin A level, HepG2 cells were exposed for $72 \mathrm{~h}$ to different concentrations of

oleate (Fig. 5e). Oleate increased mTORC1/4E-BP1 phosphorylation and cyclin A level at low concentrations with a maximal increase seen at $50 \mu \mathrm{mol} / 1$ oleate. Starting from $100 \mu \mathrm{mol} / 1$, these effects decreased. Hence, the two concentrations chosen for our experiments seem to be appropriate because at $50 \mu \mathrm{mol} / \mathrm{l}$ the mTOR pathway is fully activated while at $1 \mathrm{mmol} / 1$ it is severely inhibited.

To confirm that mTORC1 activation supported oleateinduced proliferation of HepG2 cells, we analysed the effect of rapamycin on the proliferation induced by a $72 \mathrm{~h}$ treatment with $50 \mu \mathrm{mol} / \mathrm{l}$ oleate. Surprisingly, rapamycin treatment alone efficiently inhibited the proliferation of HepG2 cells and reduced the level of cyclin A, but was without effect in the presence of oleate (Fig. 6a, b). Hence, we reasoned that oleate rendered a component of the mTORC1 pathway insensitive to rapamycin. Indeed, it has been shown recently that cap-dependent translation could occur despite rapamycin treatment and S6K inhibition, and that rapamycin resistance may be specific to the mTORC1/ 4E-BPs arm of the mTORC1 pathway [24]. As seen in Fig. $6 \mathrm{c}$ and d, in the presence of oleate, rapamycin reduced the phosphorylation of the ribosomal S6 protein to control levels, but not that of 4E-BP1.

Oleate increases cyclin A level and mTORC1 activity through PLD activity The existence of an oleate-sensitive PLD that is only stimulated by low concentrations of oleate [15] and the notion that PA renders mTORC1 resistant to rapamycin prompted us to examine whether oleate-induced mTORC1 activation may involve activation of PLDs. As seen in Fig. 7a, PLD activity was increased in HepG2 cells treated for $72 \mathrm{~h}$ with $50 \mu \mathrm{mol} / \mathrm{l}$, but it was decreased by $1 \mathrm{mmol} / \mathrm{l}$ oleate. Oleate had no effect on PLD1 or PLD2 mRNAs (data not shown). Moreover, inhibition of PLDmediated PA production by 1-butanol abolished mTORC1 activation assessed by mTOR, S6 and 4E-BP1 phosphorylation (Fig. 7b-d). Furthermore, treatment with 1-butanol blunted the increase in cyclin A protein levels induced by $50 \mu \mathrm{mol} / 1$ oleate compared with the control condition (Fig. 7e).

Oleate activates mTORC1 and favours rapamycin resistance in SK-Hep1 hepatoma cells To exclude the possibility that oleate's main effects could be unique to HepG2 cells, we performed similar experiments on SK-Hep1 cells. Indeed, compared with the basal condition, $50 \mu \mathrm{mol} / \mathrm{l}$ oleate addition for $48 \mathrm{~h}$ robustly activated the $\mathrm{mTORC} 1$ pathway and increased the cyclin A level (Fig. 8a-e). However, $1 \mathrm{mmol} / \mathrm{l}$ oleate also induced a modest, albeit not significant, increase in mTOR phosphorylation and cyclin A level, and a significant increase in S6 and 4E-BP1 phosphorylation, compared with the basal condition. These differences in the effect of $1 \mathrm{mmol} / \mathrm{l}$ oleate between HepG2 and SK- 
Fig. 4 Oleic acid (OA) regulates the PKB and ERK signalling pathways. a Representative blots showing the levels of PKB and ERK phosphorylation and of PTEN in HepG2 cells exposed to BSA, $50 \mu \mathrm{mol} / 1$ or $1 \mathrm{mmol} / 1 \mathrm{OA}$ or $10 \%$ (vol./vol.) FCS for $24 \mathrm{~h}$. b-e Quantification of PKB phosphorylation at T308 (b) and S473 (c), ERK phosphorylation (d) and PTEN (e) level in HepG2 cells exposed to BSA, $50 \mu \mathrm{mol} / 1$ or $1 \mathrm{mmol} / 1 \mathrm{OA}$ for $24 \mathrm{~h}(n=3)$. Results in b-e were normalised with respect to the BSA condition. ${ }^{*} p<0.05$, $*^{*} p<0.01, * * * p<0.001$, ${ }^{\dagger} p=0.051,{ }^{\star} p=0.052,{ }^{\circledR} p=0.059$

Fig. 5 Concentration-dependent effect of oleic acid (OA) on the mTOR signalling pathway. a Representative blots showing the level of pS2448 mTOR (pmTOR), mTOR, phosphorylated S6 (pS6), S6 and pThr37/46 4E-BP1 in HepG2 cells exposed to BSA, $50 \mu \mathrm{mol} / 1$ or $1 \mathrm{mmol} / 1 \mathrm{OA}$ or $10 \%$ (vol./vol.) FCS for $24 \mathrm{~h}$. b-d Quantification of pS2448 mTOR (b), pS6 (c) and pThr37/46 4E-BP1 (d) in HepG2 cells exposed to BSA, $50 \mu \mathrm{mol} / 1$ or $1 \mathrm{mmol} / \mathrm{l} \mathrm{OA}$ for $24 \mathrm{~h}(n=3)$. Results in b-d were normalised with respect to the BSA condition. e Representative blots showing the levels of cyclin A and pThr37/46 4E-BP1 in HepG2 cells exposed to BSA or $20,50,100,500$ or $1000 \mu \mathrm{mol} / 1 \mathrm{OA}$ for $72 \mathrm{~h}(n=3)$. ${ }^{*} p<0.05,{ }^{* *} p<0.01, * * * p<0.001$

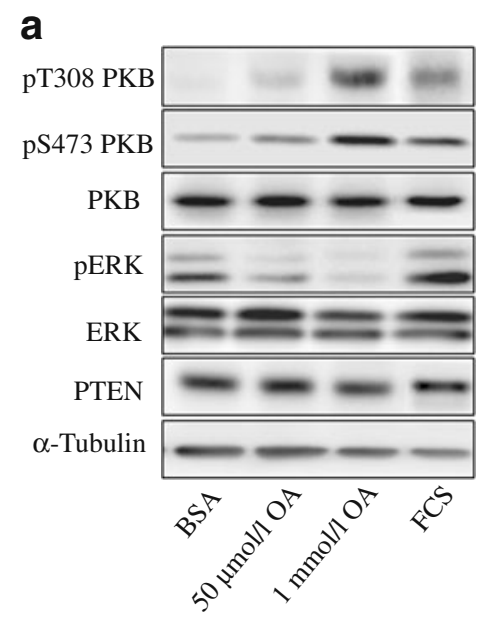

b

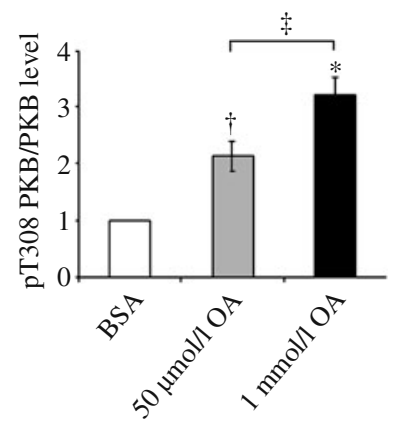

C

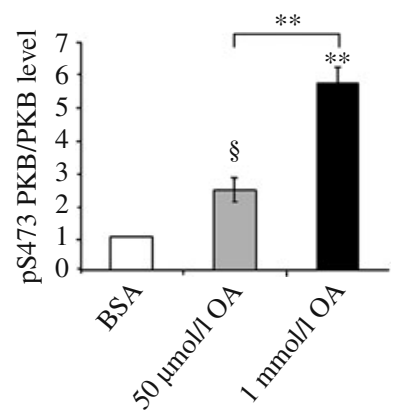

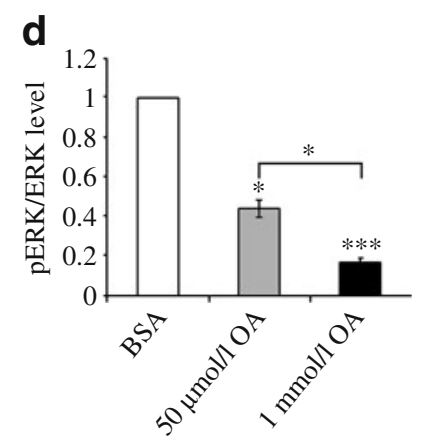

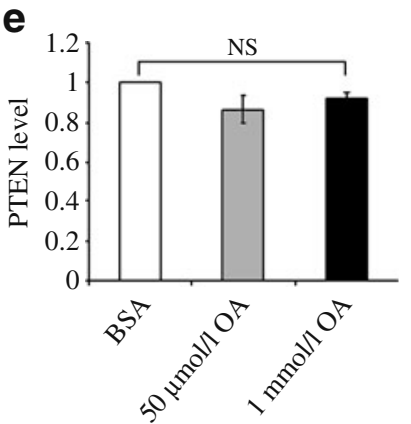

a
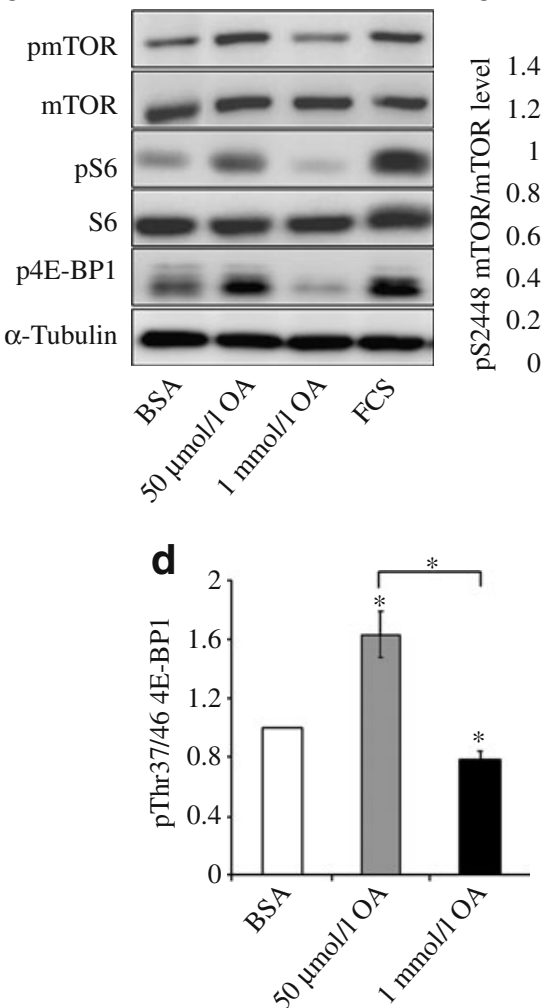

b

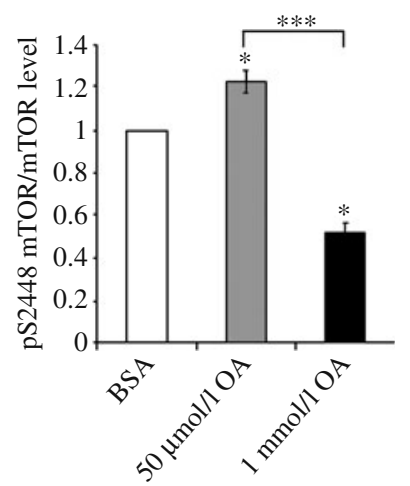

e

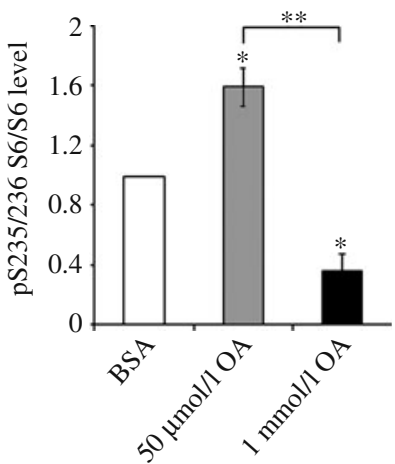

$\mathrm{OA}(\mu \mathrm{mol} / \mathrm{l}) \quad-\quad 20 \quad 50 \quad 100 \quad 500 \quad 1,000$

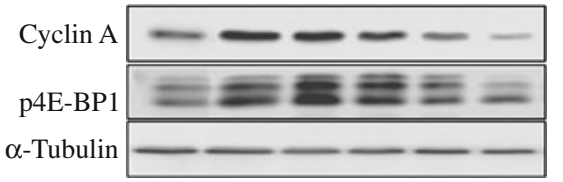




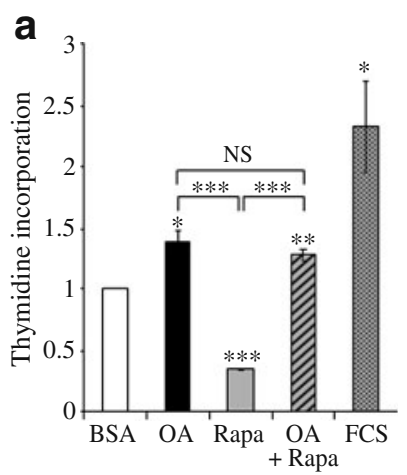

b
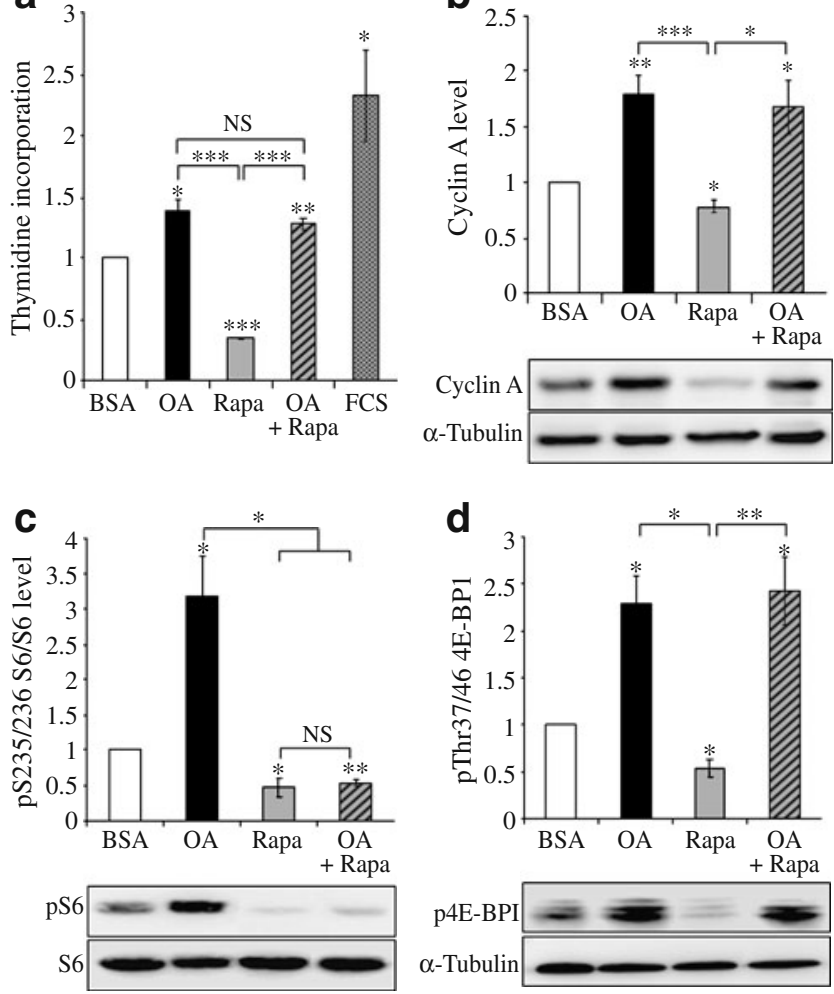

Fig. 6 Selective rapamycin resistance in the presence of $50 \mu \mathrm{mol} / 1$ oleic acid (OA) in HepG2 cells. a Proliferation of HepG2 cells exposed to BSA, $50 \mu \mathrm{mol} / 1 \mathrm{OA}, 50 \mathrm{nmol} / 1 \mathrm{rapamycin}$ (Rapa), $50 \mu \mathrm{mol} / 1 \mathrm{OA}$ plus $50 \mathrm{nmol} / \mathrm{l}$ rapamycin or $10 \%$ (vol./vol.) FCS for $72 \mathrm{~h}$ assessed by $\left[{ }^{3} \mathrm{H}\right]$ thymidine incorporation $(n=3)$. b Representative blots and quantification of cyclin A level in HepG2 cells exposed to BSA, $50 \mu \mathrm{mol} /$ $1 \mathrm{OA}, 50 \mathrm{nmol} / 1 \mathrm{rapamycin}$ or $50 \mu \mathrm{mol} / \mathrm{l} \mathrm{OA}$ plus $50 \mathrm{nmol} / 1$ rapamycin for $72 \mathrm{~h}(n=4)$. c, d Representative blots and quantification of phosphorylated S6 (pS6) (c) and pThr37/46 4E-BP1 (d) in HepG2 cells exposed to BSA, $50 \mu \mathrm{mol} / 1 \mathrm{OA}, 50 \mathrm{nmol} / 1 \mathrm{rapamycin}$ or $50 \mu \mathrm{mol} /$ $1 \mathrm{OA}$ plus $50 \mathrm{nmol} / 1$ rapamycin for $72 \mathrm{~h}(n=3)$. Results were normalised with respect to the BSA condition. ${ }^{*} p<0.05,{ }^{*} p<0.01,{ }^{*} * * p<0.001$

Hep1 cells can be attributed to the low basal level of mTOR activation in the latter cell line.

To investigate whether oleate could also induce rapamycin resistance in this model, SK-Hep1 cells were treated concomitantly with $50 \mu \mathrm{mol} / 1$ oleate and $50 \mathrm{nmol} / 1 \mathrm{rapa}-$ mycin for $48 \mathrm{~h}$ (Fig. 9a-c). Interestingly, 4E-BP1 phosphorylation and cyclin A level were quite insensitive to rapamycin in the presence of oleate, whereas S6 phosphorylation was not. Overall, these findings are similar to the observations made in HepG2 cells.

\section{Discussion}

Although the link between overweight, obesity and cancer is well established, the underlying mechanisms remain obscure. Among other hypotheses [25], the fact that most obese patients are insulin resistant led to the idea that their compensatory hyperinsulinaemia may act as a cell growth stimulus. Another explanation could involve the direct effects of NEFA on the liver and potentially on other sensitive organs. Indeed, in the context of obesityassociated insulin resistance, there is both an increase in the systemic release of NEFA stored by adipose tissue and an increase in hepatic lipogenesis. Concerning the release of NEFA by adipose tissue, a metabolomic study has revealed an increase in the circulating levels of oleate from $150 \mu \mathrm{mol} / 1$ in lean humans to $200 \mu \mathrm{mol} / 1$ in obese ones [26]. Although the local tissue concentration of oleate in a

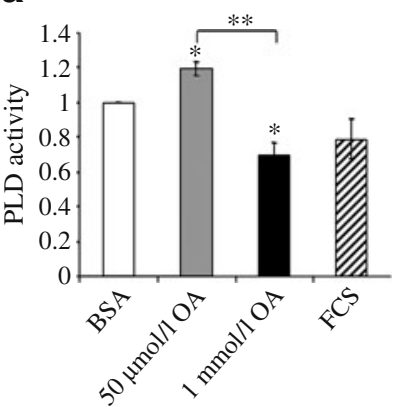

C

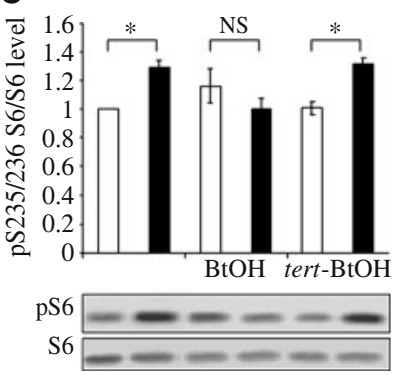

b

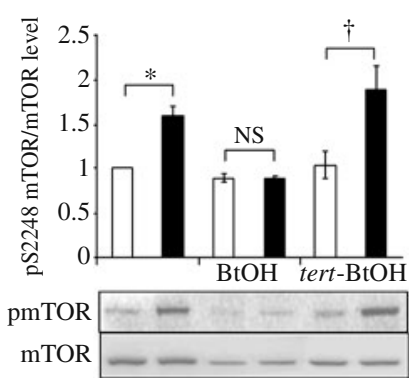

d
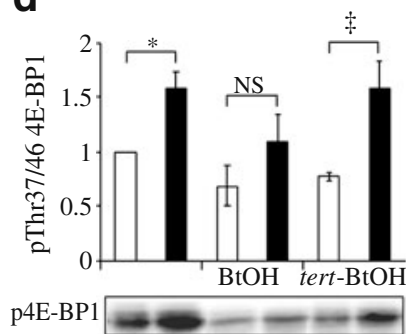

$\alpha$-Tubulin $\ldots \ldots$

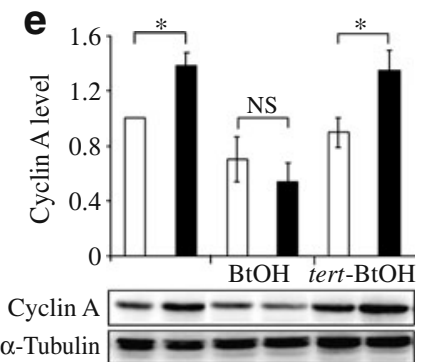

Fig. 7 Oleic acid (OA)-mediated PLD activation regulates mTOR sensitivity to rapamycin, and cyclin A level. a PLD activity in HepG2 cells exposed to BSA, $50 \mu \mathrm{mol} / 1$ or $1 \mathrm{mmol} / 1 \mathrm{OA}$ or $10 \%$ (vol./vol.) FCS for $72 \mathrm{~h}(n=3)$. Results were normalised to the protein content of each sample. b-e Representative blots and quantification of phosphorylated S2448 mTOR (pS2448 mTOR) (b), pS235/233 S6 (c), pThr37/46 4E-BP1 (d) and cyclin A (e) level in HepG2 cells exposed to BSA or $50 \mu \mathrm{mol} / 1 \mathrm{OA}$, and with or without 1-butanol or tertbutanol for $72 \mathrm{~h}$. Results were normalised with respect to the BSA condition. White bars, BSA; black bars, $50 \mu \mathrm{mol} / 1 \mathrm{OA})(n=3)$. Bt-OH, 1-butanol; tert-BtOH, tert-butanol. ${ }^{*} p<0.05,{ }^{* *} p<0.01,{ }^{\dagger} p=0.06$, ${ }^{\ddagger} p=0.051$ 
Fig. 8 Oleic acid (OA)-mediated mTORC1 activation and cyclin A level in SK-Hep1 cells. a Representative blots showing the level of phosphorylated S2448 mTOR (pS2448 mTOR), mTOR, pS6, $\mathrm{S} 6$ and $\mathrm{pThr} 37 / 46$ 4E-BP1 and cyclin A level in SK-HEP1 cells exposed to BSA, $50 \mu \mathrm{mol} / 1$ or $1 \mathrm{mmol} / \mathrm{l} \mathrm{OA}$ or $10 \%$ (vol./vol.) FCS for $48 \mathrm{~h}$. b-e Quantification of pS2448 mTOR (b), pS6 (c), pThr37/46 4E-BP1 (d) and cyclin A (e) in SK-HEP1 cells exposed to BSA, $50 \mu \mathrm{mol} / 1$ or $1 \mathrm{mmol} / \mathrm{l} \mathrm{OA}$ for $48 \mathrm{~h}(n=3)$. Results in $\mathbf{b}$-e were normalised with respect to the BSA condition. $* p<0.05, * * p<0.01$, $* * * p<0.001$

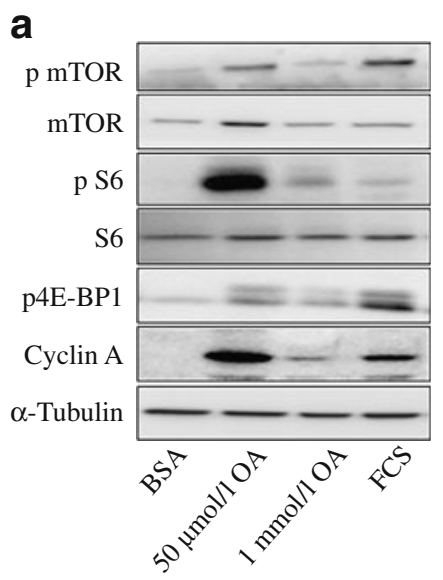

b

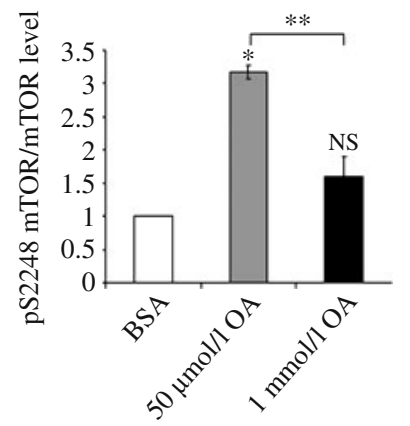

C

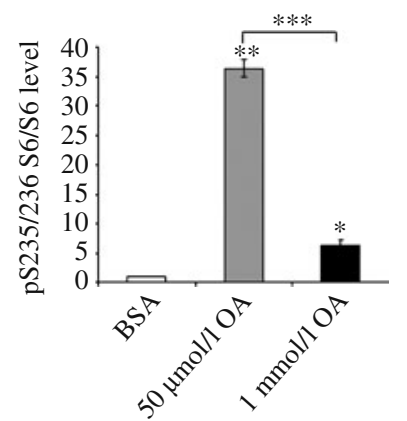

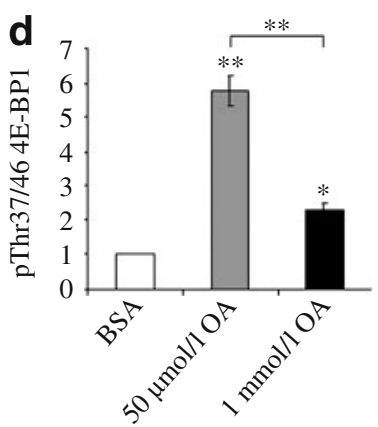

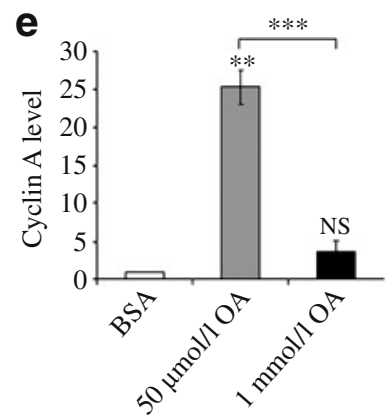

lean and obese people is unknown, this $50 \mu \mathrm{mol} / 1$ increase may in part explain the increased risk of cancer found in obese people. This fact is highly relevant to our present work, which shows a specific proliferative effect of oleate at this concentration on the HepG2 hepatocarcinoma cell line.

The increase in liver lipogenesis observed in the context of obesity has remained puzzling until recently because it was thought to rely on PKB activation, which is blunted in the context of insulin resistance [27]. A recent study showing that mTORC1 drives lipogenesis in the presence of insulin resistance helps to explain the paradox [28]. Again, this is relevant to our work and that of others [7] showing that oleate, one of the major triacylglycerol building blocks, is able to activate mTORC1. It suggests that excess NEFA taken up by the liver may favour lipogenesis and hepatic steatosis by activating mTORC1. Hence, oleate should be added to the list of nutrients whose availability is sensed by mTOR to adapt cell metabolism accordingly, notably in lipid biosynthesis [29].

Concerning the exact mechanism by which oleate increases hepatoma proliferation, Vinciguerra et al. [7]

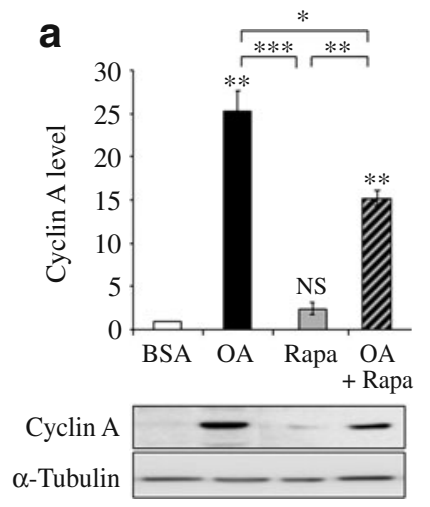

Fig. 9 Selective rapamycin resistance in the presence of $50 \mu \mathrm{mol} / 1$ oleic acid (OA) in Sk-Hep1 cells. a-c Representative blot and quantification of cyclin A level (a), phosphorylation of S6 (b) and phosphorylation of 4E-BP1 (c) in SK-Hep1 cells exposed to BSA, $50 \mu \mathrm{mol} / 1 \mathrm{OA}$,
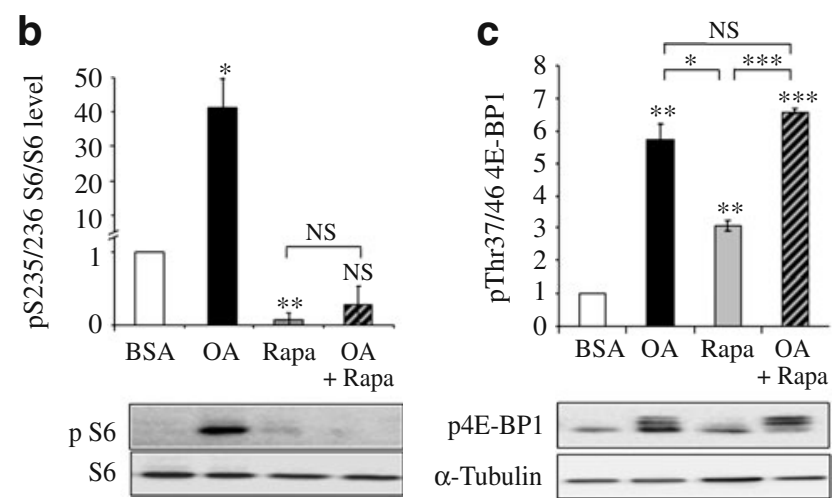

$50 \mathrm{nmol} / 1$ rapamycin (Rapa) or $50 \mu \mathrm{mol} / 1 \mathrm{OA}$ plus $50 \mathrm{nmol} / 1$ rapamycin for $48 \mathrm{~h}(n=3)$. Results were normalised with respect to the BSA condition. ${ }^{*} p<0.05,{ }^{* *} p<0.01, * * * p<0.001$ 
proposed that it involves a mTOR driven feedback loop restraining PTEN production and hence activating PKB. As pointed out in another study [8], however, this explanation falls short in the context of obese insulin-resistant people, given that PKB activation is blunted. Indeed, we are in agreement with this view since we did not find downregulation of the PTEN level as a potential explanation for the proliferative effects of oleate. Instead, the activation of mTORC1 by oleate per se could exert a proliferative action, given its known growth-promoting role and its function in translation regulation. Indeed, the fact that oleate regulates the levels of cyclin A and E, components involved in Sphase entry, without affecting the corresponding mRNAs is in agreement with this. Besides mTORC1, other major signal transduction pathways may participate in the proliferative effect of oleate. This could be the case for the ERK pathway, the activation of which was consistently found to be reduced by oleate in our study. Indeed, decreasing the activation of this pathway in HepG2 cells has been shown previously to increase proliferation, whereas stimulation of this pathway underlies HGF-induced inhibition of these cells [30].

We further explored the mechanism by which oleate activates mTOR and focused our efforts on PLDs, a class of enzymes previously shown to be specifically activated by low concentrations of oleate [15] and whose product, PA, regulates mTOR activation and sensitivity to rapamycin [16]. Consistent with our hypothesis, the low and high concentrations of oleate were found to increase and decrease PLD activity, respectively. Furthermore, the activation of the mTORC1 pathway and the increase in cyclin A level induced by oleate were both prevented by concomitant treatment with 1-butanol, which inhibits PLDmediated PA production. This was not seen with tertbutanol used as a control. The blockade of the growthpromoting effect of oleate by 1-butanol might have clinical relevance. Indeed, of the only two amino acid changes conferring constitutive activation of mTORC1 discovered to date in human cancers, one is a mutation rendering mTOR resistant to PLD inhibition by 1-butanol [31], probably by altering the dependence of mTORC1 on PA. The fact that such a mutation occurs underscores the importance of mTOR activation by PLDs in the oncogenic process.

An additional key observation we made concerns the resistance of mTORC1 to rapamycin conferred by oleate. Despite initial high expectations, rapamycin and its derived molecules have been shown to have reduced therapeutic benefits because of the phenomenon of rapamycin resistance, whose molecular basis remains obscure. Indeed, in some cancer cells rapamycin is effective in inhibiting mTOR, but with a benefit that is limited by the concomitant relief of the Ras/mitogen-activated protein kinase (MAPK) pathway from an mTORC1-initiated negative feedback loop [32]. This suggested a promising approach to HCC therapy consisting of a combination of mTORC1 and Ras/MAPK inhibitors [33]. Additional explanations for rapamycin resistance may involve mTORC2-dependent outputs, because this complex, which is involved in PKB activation by phosphorylation of serine 473 , has been shown to be less sensitive to rapamycin inhibition compared with mTORC1 [12]. However, our finding that PKB phosphorylation of S473 is increased not only by $50 \mu \mathrm{mol} / 1$ but also by $1 \mathrm{mmol} / 1$ oleate, which inhibits proliferation, argues against this hypothesis. Recently, another study implicated rapamycin-insensitive mTORC1 outputs in the mechanism of rapamycin resistance, specifically those of the mTORC1/4E-BP1 arm of the mTORC1 pathway [24]. Although both S6K and 4E-BP initiate translation in response to mTOR activation, they seem to act on specific mRNA populations. Although this view has been challenged recently [34], S6K is thought to specifically favour the translation of mRNA species containing an oligopyrimidine tract at the $5^{\prime}$ terminus (TOP-mRNAs), such as those encoding ribosomal proteins or elongation factors. The phosphorylation and dissociation of 4E-BP from eukaryotic translation initiation factor $4 \mathrm{E}$ (eIF-4E) allows the translation of cap-containing mRNAs and of mRNAs with $5^{\prime}$ secondary structures, which frequently encode proteins involved in proliferation [35]. Remarkably, our results showing that 4E-BP1 is still phosphorylated despite inhibition of S6K by rapamycin are in agreement with 4E-BP1 being a key target of rapamycin resistance. When HepG2 cells were treated concomitantly with oleate and butanol, we observed a reduction in the phosphorylation level not only of mTOR and ribosomal protein S6 but also of 4E-BP1, and in cyclin A level. These findings suggest a causal relationship since 4E-BP1 is a translational regulator and since we found that increased cyclin A production involves a post-transcriptional mechanism.

The key observations of our present work, i.e. the concentration-dependent effect of oleate on cell growth and the selective rapamycin resistance, are not unique to HepG2 cells, as we found the same general picture in the SK-Hep1 human hepatocarcinoma cell line.

Given the major challenge in treating liver cancer, it is tempting to extrapolate our findings to the human disease. Considering that physiologically relevant concentrations of oleate confer rapamycin resistance, one would expect that in obese patients suffering from liver cancer the use of this drug will have limited therapeutic success, unless specific dietary recommendations are implemented. In addition, our finding that oleate activates the mTOR pathway may be relevant to liver regeneration, given that NEFA uptake and mTOR activation are essential to this process [36, 37]. Our work begets the clinically important question of whether 
the proliferative effect of oleate applies to the whole spectrum of obesity-associated cancers, notably those of epithelial origin, or only part of it. Indeed, monounsaturated fatty acids have been shown to be required for prostate cancer progression in mice [38], and recent observations suggest a rather large role of rapamycin resistance towards the mTORC1/4E-BP arm in breast, colon and cervical cancer cell lines [39], which are derived from epithelial human tumours known to belong to the gamut of obesityassociated cancers. Thus, the concurrent occurrence of oleate-induced proliferation and rapamycin resistance could be considered a novel paradigm of epithelial-derived cancers.

Acknowledgements C. Arous was supported by a PhD fellowship from the Association pour la Recherche contre le Cancer (ARC, 20092010) and the Ligue Nationale Contre le Cancer (LNCC, 2010-2011). Our research was supported by the Institut National de la Santé et de la Recherche Médicale, the Université de Nice-Sophia-Antipolis, the Conseil Général des Alpes-Maritimes and the Centre Hospitalier Universitaire de Nice.

Duality of interest The authors declare that there is no duality of interest associated with this manuscript.

\section{References}

1. Whittaker S, Marais R, Zhu AX (2010) The role of signaling pathways in the development and treatment of hepatocellular carcinoma. Oncogene 29:4989-5005

2. Fausto N (1999) Mouse liver tumorigenesis: models, mechanisms, and relevance to human disease. Semin Liver Dis 19:243-252

3. Caldwell SH, Crespo DM, Kang HS, Al-Osaimi AM (2004) Obesity and hepatocellular carcinoma. Gastroenterology 127:S97S103

4. Shteyer E, Liao Y, Muglia LJ, Hruz PW, Rudnick DA (2004) Disruption of hepatic adipogenesis is associated with impaired liver regeneration in mice. Hepatology 40:1322-1332

5. Tiniakos DG, Vos MB, Brunt EM (2010) Nonalcoholic fatty liver disease: pathology and pathogenesis. Annu Rev Pathol 5:145-171

6. Malhi H, Bronk SF, Werneburg NW, Gores GJ (2006) Free fatty acids induce JNK-dependent hepatocyte lipoapoptosis. J Biol Chem 281:12093-12101

7. Vinciguerra M, Carrozzino F, Peyrou M et al (2009) Unsaturated fatty acids promote hepatoma proliferation and progression through downregulation of the tumor suppressor PTEN. J Hepatol 50:1132-1141

8. Park EJ, Lee JH, Yu GY et al (2010) Dietary and genetic obesity promote liver inflammation and tumorigenesis by enhancing IL-6 and TNF expression. Cell 140:197-208

9. Fingar DC, Richardson CJ, Tee AR, Cheatham L, Tsou C, Blenis J (2004) mTOR controls cell cycle progression through its cell growth effectors S6K1 and 4E-BP1/eukaryotic translation initiation factor 4E. Mol Cell Biol 24:200-216

10. Mordier S, Iynedjian PB (2007) Activation of mammalian target of rapamycin complex 1 and insulin resistance induced by palmitate in hepatocytes. Biochem Biophys Res Commun 362:206-211

11. Wullschleger S, Loewith R, Hall MN (2006) TOR signaling in growth and metabolism. Cell 124:471-484
12. Toschi A, Lee E, Xu L, Garcia A, Gadir N, Foster DA (2009) Regulation of mTORC1 and mTORC2 complex assembly by phosphatidic acid: competition with rapamycin. Mol Cell Biol 29:1411-1420

13. Fang Y, Vilella-Bach M, Bachmann R, Flanigan A, Chen J (2001) phosphatidic acid-mediated mitogenic activation of mTOR signaling. Science 294:1942-1945

14. Lehman N, Ledford B, Di Fulvio M, Frondorf K, McPhail LC, Gomez-Cambronero J (2007) Phospholipase D2-derived phosphatidic acid binds to and activates ribosomal p70 S6 kinase independently of mTOR. FASEB J 21:1075-1087

15. Kim JH, Kim Y, Lee SD et al (1999) Selective activation of phospholipase D2 by unsaturated fatty acid. FEBS Lett 454:42-46

16. Foster DA (2009) Phosphatidic acid signaling to mTOR: signals for the survival of human cancer cells. Biochim Biophys Acta 1791:949-955

17. Toschi A, Lee E, Thompson S et al (2010) Phospholipase DmTOR requirement for the Warburg effect in human cancer cells. Cancer Lett 299:72-79

18. DeBerardinis RJ, Lum JJ, Hatzivassiliou G, Thompson CB (2008) The biology of cancer: metabolic reprogramming fuels cell growth and proliferation. Cell Metab 7:11-20

19. Ramirez-Zacarias JL, Castro-Munozledo F, Kuri-Harcuch W (1992) Quantitation of adipose conversion and triglycerides by staining intracytoplasmic lipids with Oil red O. Histochemistry 97:493-497

20. Chaussade C, Pirola L, Bonnafous S et al (2003) Expression of myotubularin by an adenoviral vector demonstrates its function as a phosphatidylinositol 3-phosphate [PtdIns(3)P] phosphatase in muscle cell lines: involvement of PtdIns(3)P in insulin-stimulated glucose transport. Mol Endocrinol 17:2448-2460

21. Tajima H, Matsumoto K, Nakamura T (1991) Hepatocyte growth factor has potent anti-proliferative activity in various tumor cell lines. FEBS Lett 291:229-232

22. Masaki T, Shiratori Y, Rengifo W et al (2003) Cyclins and cyclindependent kinases: comparative study of hepatocellular carcinoma vs cirrhosis. Hepatology 37:534-543

23. Huynh H, Do PT, Nguyen TH et al (2004) Extracellular signalregulated kinase induces cyclin D1 and Cdk-2 expression and phosphorylation of retinoblastoma in hepatocellular carcinoma. Int J Oncol 25:1839-1847

24. Choo AY, Yoon SO, Kim SG, Roux PP, Blenis J (2008) Rapamycin differentially inhibits S6Ks and 4E-BP1 to mediate cell-type-specific repression of mRNA translation. Proc Natl Acad Sci USA 105:17414-17419

25. Calle EE, Kaaks R (2004) Overweight, obesity and cancer: epidemiological evidence and proposed mechanisms. Nat Rev Cancer 4:579-591

26. Newgard CB, An J, Bain JR et al (2009) A branched-chain amino acid-related metabolic signature that differentiates obese and lean humans and contributes to insulin resistance. Cell Metab 9:311326

27. Shimomura I, Matsuda M, Hammer RE, Bashmakov Y, Brown MS, Goldstein JL (2000) Decreased IRS-2 and increased SREBP$1 \mathrm{c}$ lead to mixed insulin resistance and sensitivity in livers of lipodystrophic and ob/ob mice. Mol Cell 6:77-86

28. Li S, Brown MS, Goldstein JL (2010) Bifurcation of insulin signaling pathway in rat liver: mTORC1 required for stimulation of lipogenesis, but not inhibition of gluconeogenesis. Proc Natl Acad Sci USA 107:3441-3446

29. Laplante M, Sabatini DM (2009) An emerging role of mTOR in lipid biosynthesis. Curr Biol 19:R1046-R1052

30. Tsukada Y, Miyazawa K, Kitamura N (2001) High intensity ERK signal mediates hepatocyte growth factor-induced proliferation inhibition of the human hepatocellular carcinoma cell line HepG2. J Biol Chem 276:40968-40976 
31. Sato T, Nakashima A, Guo L, Coffman K, Tamanoi F (2010) Single amino-acid changes that confer constitutive activation of mTOR are discovered in human cancer. Oncogene 29:27462752

32. Carracedo A, Ma L, Teruya-Feldstein J et al (2008) Inhibition of mTORC1 leads to MAPK pathway activation through a PI3Kdependent feedback loop in human cancer. J Clin Invest 118:3065-3074

33. Newell P, Toffanin S, Villanueva A et al (2009) Ras pathway activation in hepatocellular carcinoma and anti-tumoral effect of combined sorafenib and rapamycin in vivo. J Hepatol 51:725-733

34. Patursky-Polischuk I, Stolovich-Rain M, Hausner-Hanochi M et al (2009) The TSC-mTOR pathway mediates translational activation of TOP mRNAs by insulin largely in a raptor- or rictorindependent manner. Mol Cell Biol 29:640-649
35. Sonenberg N, Gingras A-C (1998) The mRNA 5' cap-binding protein eIF4E and control of cell growth. Curr Opin Cell Biol 10:268-275

36. Jiang YP, Ballou LM, Lin RZ (2001) Rapamycin-insensitive regulation of $4 \mathrm{e}-\mathrm{BP} 1$ in regenerating rat liver. $\mathrm{J}$ Biol Chem 276:10943-10951

37. Brasaemle DL (2006) Cell biology: Enhanced: a metabolic push to proliferate. Science 313:1581-1582

38. Fritz V, Benfodda Z, Rodier G et al (2010) Abrogation of de novo lipogenesis by stearoyl-CoA desaturase 1 inhibition interferes with oncogenic signaling and blocks prostate cancer progression in mice. Mol Cancer Ther 9:1740-1754

39. Thoreen CC, Kang SA, Chang JW et al (2009) An ATP-competitive mammalian target of rapamycin inhibitor reveals rapamycin-resistant functions of mTORC1. J Biol Chem 284:8023-8032 